msh-mss Mathématiques et sciences humaines

146 | Été 1999

Varia

\title{
Prévisions par arbres de classification
}

Prediction using classification trees

Badih Ghattas

\section{OpenEdition}

Journals

Édition électronique

URL : http://journals.openedition.org/msh/2787

DOI : $10.4000 /$ msh. 2787

ISSN : 1950-6821

\section{Éditeur}

Centre d'analyse et de mathématique sociales de l'EHESS

Édition imprimée

Date de publication : 1 mars 1999

ISSN : 0987-6936

\section{Référence électronique}

Badih Ghattas, «Prévisions par arbres de classification », Mathématiques et sciences humaines [En ligne], 146 | Été 1999, mis en ligne le 10 février 2006, consulté le 23 juillet 2020. URL : http:// journals.openedition.org/msh/2787 ; DOI : https://doi.org/10.4000/msh.2787

Ce document a été généré automatiquement le 23 juillet 2020

(c) École des hautes études en sciences sociales 


\section{Prévisions par arbres de classification}

Prediction using classification trees

\section{Badih Ghattas}

\section{RÉSUMÉS}

Après une présentation de la construction de prédicteurs par arbre de classification, nous nous intéressons à l'instabilité de cette méthode et proposons une méthodologie dans laquelle intervient le bootstrap. Une étude empirique détaillée illustre ce travail.

Following the tree method classification, we focus on the instability of the method and suggest a technique where the bootstrap is used. A detailed empirical study is illustrated in this paper.

\section{INDEX}

Mots-clés : agrégation de classificateurs, arbres de classification, bootstrap, CART, ozone, prévision

Keywords : aggregating classifiers, classification trees, prediction, bootstrap, CART, ozone Thèmes : arbres, classification - partition, données (analyse des), inférence, méthodologie, ordres et préordres 